Open Access

\title{
What determines "giving birth to a son": the social transformation of how institution and culture affect women's fertility choices
}

Wu Ying ${ }^{{ }^{*}}$, Yang Yiyin ${ }^{2}$, Wei Xiaojiang ${ }^{1}$ and Chen $\mathrm{En}^{3}$

\author{
* Correspondence: \\ nolung@163.com \\ ${ }^{1}$ School of Ethnology and \\ Sociology, Minzu University of \\ China, Beijing, China \\ Full list of author information is \\ available at the end of the article
}

\begin{abstract}
Since the implementation of China's one-child family planning policy in 1980, the fertility culture and governmental institutions have become two important factors that determine women's fertility selection. In accordance with the influence of the traditional fertility culture and the family planning policy, we divide communities into four types: (1) "strong institution and strong culture," which corresponds to the village-turned-community; (2) "strong institution and weak culture," which corresponds to the danwei community; (3) "weak institution and strong culture," which corresponds to the current labor force-drained rural community; and (4) "weak institution and weak culture". Based on the theories of cultural and social psychology and neo-institutionalism, we explore the influence of the fertility culture and the family planning policy on women's fertility choice, in particular, how people make choices when facing a conflict between the fertility culture and the institutions, how the new community fertility culture is constructed to sustain the implementation of the family planning policy, and how the improvement of the families' financial status affects the institutional and cultural effect on the fertility choices.
\end{abstract}

Keywords: Family planning policy, Traditional fertility culture, Women's fertility choices, Descriptive norm, Injunctive norm

\section{Women's fertility choices constrained by institutional and cultural factors}

On October 28, 2015, the Fifth Plenary Session of the CPC's (Communist Party of China) 18th Central Committee proclaimed the reform of the Chinese family planning system and the liberalization of the two-child restriction for the whole country, which allowed each couple to have two children. This proclaims a dramatic change in China's nearly 40-year fertility policy-likely improving the status quo of China's aging population structure and making possible more fertility choices for individuals and families. The implementation of the multi-year family planning policy has influenced and changed the fertility choices of many families, to a certain extent, and has also led to the transformation of fertility culture in Chinese society (Yan 2006; Guangzong 2000).

Institution and culture are two important factors determining women's fertility choices. Women, as the main body of fertility, cannot be ignored in implementing the family planning policy: In urban communities, women's fertility choice is affected by work pressure and the culture of the danwei system (Weiwen 1994; Wang 2011). In

(c) The Author(s). 2017 Open Access This article is distributed under the terms of the Creative Commons Attribution 4.0 International License (http://creativecommons.org/licenses/by/4.0/), which permits unrestricted use, distribution, and reproduction in any medium, provided you give appropriate credit to the original author(s) and the source, provide a link to the Creative Commons license, and indicate if changes were made. 
traditional rural communities, women have to face a plight that resulted in a narrow "space of birth choice" caused by the family planning policy and strong "son preference" culture (Guangzong and Wei 1995), women's right to make a fertility choice might be subject to double deprivation.

Existing studies on women and fertility mainly focus on analyzing population economics in terms of women's fertility will and fertility behavior (Hehui 1995; Hu 2010; Chen and Zhang 2003). Among these studies, birth sequence, education level, health status, income, and family status are often analyzed as influential independent variables, while fertility policies and the effects of the traditional fertility culture are rarely expressed in the sophisticated quantitative models, or, only as background factors and reference variables to differentiate periods of time. Series studies from Zhu et al. (Zhu and Shuzhuo 1997; Hu and Zhu 1996) discussed how the family planning policy affected women. These studies suggested that the impact of the family planning policy on women can be divided into positive aspects and negative aspects. Positive aspects can be seen in the following: the reduction in the number of births can shorten women's reproductive cycle, providing more opportunity for women to acquire higher education and to develop herself by participating in social life; negative effects are reflected in the bodily harm caused by birth control or contraception, and the physical and mental harm caused by improper behavior from the policy enforcement department; more importantly, birth control makes women who have only daughters face lifelong pressure from family and culture.

In addition to institutional factors, traditional birth culture is also an important variable affecting the fertility behavior of Chinese people. Yinhe (2009) points out in her "Fertility and Village Culture" that the theory of cost-utility that applies to the fertility problem of the Western population does not have sufficient explanatory power to help understand Chinese fertility behavior. In traditional rural communities, fertility is related to people's production, while endowment and continuation of a patriarchal clan are part of people's cultural practices (Wang 1993). As a result, the function of fertility in continuing the clan means that people suffer the constraints of sharing fertility culture in a village environment dominated by "information sharing," "limited scope of activities," "less mobility," and "competition and convergence exist in members" (Yinhe 2009; Guangzong 2000). Some researchers begin to explore how traditional fertility culture deprives women of their rights through the birth process. As an example, the All-China Women's Federation and "Peasant Woman" magazine together compile a book entitled "My Birth Story," which consists of interviews on 28 cases. The book describes how son preference and other concepts from traditional fertility culture are accepted and internalized by family members, thereby limiting and depriving women of their rights as independent individuals (Xie 2010).

In summary, there have been studies on the process of mutual coordination and construction between family planning system and fertility culture (Guangzong 2000; Yinhe 2009; Yan 2006), the possibility of adjusting family planning policy in accordance with the boundedness of traditional fertility culture (Zhen and Junjie 1997), and people's fertility choice when the fertility institution conflicts with the cultural norms of continuing the family line (Yusheng 2009). However, fewer studies take as a subject of research how fertility institutions and traditional fertility culture together have influenced women's fertility choices. In addition, given the background of China's social 
transformation, social mobility is increasing and the number of female workers is increasing as Chinese urbanization proceeds. In this context, the effect of family planning policy and traditional fertility culture on women's fertility choice is also changing, resulting in a range of appearances and shapes. The discussion of this process is also of practical significance. This paper will discuss the above issues based on the existing research.

\section{How institution and culture affect women's fertility choices in the process of social transformation}

In order to construct a clear research hypothesis, this part will focus on the following two aspects in reviewing previous research: First, for the nearly 40-year period during which family planning policy was implemented, this research considers changes occurring in the institutional and cultural factors that affect fertility decision-making and the types of mutual constructive relationship exists between them; second, this research also considers the types of communities that best represent the typical characteristics of the times to reflect the social changes of the past 40 years and how institution and culture in different community environments influence people's fertility decisionmaking. In a number of studies on social governance, we can see that culture, as an informal norm, has the function of supplementing and strengthening the formal institution. For example, Prasenjit (2010) proposes "cultural network of power" to examine how the "patriarchal clan," informal "leisure meeting," "the association of water conservancy," and sacrifice activities function as substitutes for a formal institution in handling grassroots rural politics and financial affairs in rural areas of the North China Plain. He points out that patriarchal clans, as a cultural network, have a range of control that overlaps with formal "tithing" and "Li Jia" institution. Zongzhi (2001) also discusses the overlaps between the formal judiciary and informal regulatory institutions of the Qing Dynasty. Fei (2009) also points out that China's "gentry" may have been the main force of social control and social governance during the period of the late Qing Dynasty and the Republic of China.

In addition, some scholars explore the effect on social behavior when cultural norms and formal institution collide. For example, Yusheng (2009) has discussed how institution and culture affect fertility outcomes, from the angles of implementation mechanism, organizational performance, the controlling income of social network norms, etc. According to the level of the strength of institution and culture, he divides the effects of governance into four types: social governance dominated by informal cultural norms, social governance dominated by formal institution, social governance of cultural norms coinciding with formal institution, and social governance of informal norms colliding with formal norms. He also points out that organizational performance is at its strongest when cultural norms coincide with the formal institution; on the contrary, when cultural norms and formal institutions collide, organizational performance is at its weakest. By using quantitative data, Peng's study also verified that cultural norms (i.e., informal clan organization) function to soften the rigid family planning system, resulting in an increase in the fertility rate of the patriarchal clan.

The above studies reveal a picture of how institution and culture work together to influence social behaviors. However, in the context of social changes, institution and culture are constantly changing as well, and therefore, studying the impact of institution 
and culture on social behavior based only on a time cross section is not sufficient to understand the constitutive relationship of culture and institution and the richness and diversity of their mutual effect. This paper will examine the impact on female fertility decision-making as a result of constantly adjusting the birth control institution and changing culture since the implementation of China's family planning policy in 1978 and following a timeline of nearly 40 years. This paper also chooses to examine the fertility decision because two norms create a conflict, that is, the traditional son preference fertility cultural norms and the family planning policy that aim to control the population. Studying which norm has a more profound and lasting effect for different communities' contexts will contribute to a better understanding of the interaction between culture and institution and how they affect individual behavior during times of social change.

As an external factor restraining personal behavior, each institution's implementation and adaptation over different periods and across different communities will certainly affect individual behavior. Over the past 40 years of the implementation of family planning policy, the content, methods, and efforts towards implementation were constantly being adjusted. In the 1960s and 1970s, the general family planning policy advocated "late, rare, less," and in the early 1980s, the policy changed to the "one-child" policy that put on the "brakes" to control the population (Benfeng and Jingjing 2011; Chunyuan 2000). Then, at the start of 1984, rural one-daughter households were permitted to have a second child, followed in 1985 by the city of Yicheng in Shanxi Province becoming the first batch of pilot areas to permit a second child and in 1987, the city of Jiuquan in Gansu Province passing a two-child pilot policy. Since 2000, there has been a policy change that emphasized social service. ${ }^{1}$ In 2014 , along with the "selective two-child" policy introduced in cities, some rural communities have also adopted the two-child policy, which places no limits on the gender of the first child and does not require a certain time interval to pass between the birth of the first and second child. As of October 2015, the two-child policy has been implemented throughout the country.

For nearly 40 years, cultural norms have changed according to changes in socioeconomic and community types. On the one hand, under the influence of individualism, consumerism, and social mobility, as well as the strong implementation of family planning policy which limits the number of birth, the fertility norms of son preference in traditional rural communities have changed from "The more sons, the more blessing" to "Fewer and better birth, late childbearing" (Guangzong 2000; Yan 2006; Zhu and Shuzhuo 1997; You and Zheng 2002).

On the other hand, as the influencing factors on fertility decision-making, different types of communities also need to be taken into account. Several types of fertility culture in different communities, characteristic of the historical times, are worthy to be mentioned: First, as "urbanization" continues in China, more rural communities put "village-turned-community" into practice. Rural households are changed into urban households, and the number of births change from two children born at a timed interval into only one child. However, residents' employment and lifestyle do not change greatly as a result of the urbanization process, and the traditional fertility concept of a son preference is still deeply rooted, powerfully affect people's fertility decision-making. Second, in the danwei system, welfare guarantees such as a stable wage system, good 
health care, and pension, as well as the strong promotion of family planning policy, result in a fertility culture of "one-child glory." Third, since the end of the 1990s, social mobility has been increasing across the country, the rural labor force has shrunk, and the phenomenon of the "empty nest" has appeared. As a result, the weakened family planning policy may lead to new changes in fertility norms in rural communities. At the same time, the traditional son preference concept remains, and fertility choice is presenting itself in a new form. This shows that institutional and cultural forms in different communities have different effects on people's fertility behaviors.

\section{The typology of communities based on different dimensions of institution and culture}

Based on the two dimensions of the family planning system and traditional fertility culture norms, this study divides the external community environment affecting female fertility decisions into four types (see Fig. 1). It then analyzes the institutional and cultural influences on female fertility decision for the four types of communities. The term culture used here refers to the traditional fertility cultural norm of son preference.

The first type is defined as having a community environment with strong institutional impact and where culture acts as a strong normative force and hereafter will be abbreviated as the "strong-strong" type.

In nearly 40 years of development, there were two kinds of communities in line with this type: one example consists of rural areas in the early 1980s, where the family planning policy had just been launched and the one-child policy was strongly enforced. During this period, women's fertility in rural areas was strictly restricted by the family planning system: women could not extricate themselves from the concept of son preference, and, therefore, in order to give birth to a "son", many kinds of countermeasure behaviors against the institution appeared. This was not an uncommon situation according to previous studies; for example, a similar case was recorded by Xinxiang (2004) in a study of Chencun village.

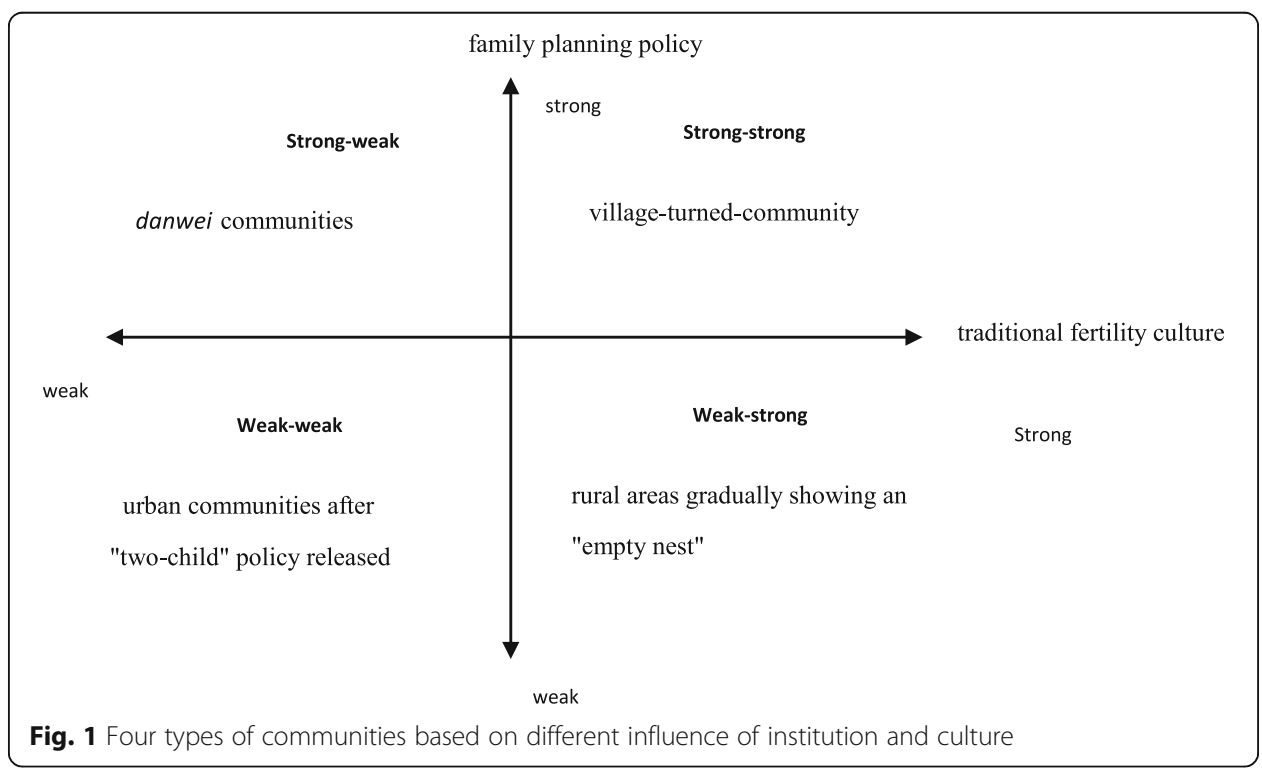


A second example arose from China's recent urbanization, with the emergence of the so-called village-turned-community. In such communities, women registered as urban residents and were constrained by the one-child policy required of urban inhabitants; meanwhile, in their lifestyle and cultural norms, they still retained characteristics of traditional rural communities and thus were subjected to traditional fertility culture norms. Existing studies rarely discuss the fertility situations that arose village-turnedcommunity. This paper will explore how women's fertility decision-making was affected by fertility norms and traditional fertility cultures in this situation.

The second type is defined as having a community environment with strong institutional impact and weak normative force of culture and is known here as the "strongweak" type. This type is represented by urban communities and danwei communities. The family planning system has a stronger influence in danwei communities, through supplementary policies such as administrative intervention, policy propaganda, and welfare system, encouraging women's occupation involvement setting up advanced models. As a result, the family planning implementation system has been strengthened, while the traditional norms of fertility culture have been weakened, ultimately resulting in new cultural norms for fertility whereby individuals strive to be in the vanguard, with fewer and better births.

The third type is defined as a community environment with weak institutional impact and strong normative force of culture, known as the "weak-strong" type. Since the late 1990s, migration labor arose in rural communities. As a result, rural areas gradually became an "empty nest". At the same time, the family planning policy came to restrain farmers' family planning behaviors less. In order to meet farmers' "fertility bottom line" of having a son, the implementation of the family planning system in rural areas began to make concessions to farmers' fertility needs (Zhen and Junjie 1997), which led to the implementation of "second child of intended-interval" policy, the nominal fines on "having more children", and similar policies. In addition, large-scale labor mobility also led to poor implementation of the family planning policy and a relatively weakened restraint on the behavior of migrant workers. Culturally, the rural pension system is imperfect, agricultural production places demands on the labor force, and the economic level of individual families has increased. In sum, all these factors led to the recovery of the traditional cultural norms for fertility, and people's desires to "give birth to a son" and "have more children" gradually increased. The weak-strong type allows us to explore the institutional and cultural effects on female fertility decision-making in rural communities with labor force outflow.

The fourth type is defined as the community environment with weak institutional impact and weak normative cultural force, abbreviated as the "weak-weak" type. The urban communities after "two-child" policy released belong to this type. In this social context, women's fertility decisions were affected by individual factors such as income, health, family support of child care, and personal and family fertility desires, with women's fertility behaviors more in line with the cost-utility logic of population economics (Becker 1987).In addition, due to weakening institutional and cultural constraints, previous quantitative models containing individual variables are more effective in interpreting and predicting fertility behavior. Because this paper focuses on the impact of culture and institution on women's fertility, the fourth type is beyond this paper's scope. 
The cases used to describe types 1 and 2 are selected from interviews from "Listening to women's voices: Oral history of family planning in China." These interviews were completed from June 2009 to November 2009. Questions included interviewees' living environment in their communities, family structure, personal living experience, fertility choice, and fertility experience. From July to August, 2015, additional case interviews were conducted for these two types. Case interviews for type 3 were completed from July to August, 2015. All interview names and hometowns used in this paper are pseudonyms.

Interviewees for village-turned-community, representing type 1 , lived in rural areas of south Henan Province, when they gave birth to a second child in 2005 or 2006, and their village changed to an urban community; as a result of "urbanization", their household registration changed from villagers to town citizens whose fertility was constrained by an urban family planning system, with only one child permitted per household. According to the local policy in 2005/2006, the "second child" of two interviewees is illegal. The interviewee representing the "danwei" community in type 2 was living in forest farm communities in the Inner Mongolia Autonomous Region, when giving birth to her son in 1988. During that time, the one-child policy was vigorously promoted in forest farm communities, and in addition to extensive and in-depth propaganda, various welfare institutions supported the implementation of the one-child policy.

Interviewees representing type 3 respectively reside in Baofeng Village of Inner Mongolia Autonomous Region and Hewan Village of Henan Province include rural women aged 29 to 34 years old, all of whom had work experiences with out-migration and had completed their fertility process. The family economic levels for these two villages are very different: Baofeng Village is located in a traditional poverty-stricken county and villagers had low incomes; the income of Hewan is generally high.

\section{Women's fertility choices in different types of communities}

Women's fertility choices in "strong institution and strong culture" communities: to meet the fertility bottom line first

\section{Environment of village-turned-communities}

Village-turned-community represents a typical case with strong influence both from the family planning system and the traditional birth culture.

This type of community arose naturally from the process of urbanization, which caused changes in household registration, residential space, and residents' income sources, while changes of living style, social norms, and culture values lagged behind (Wu 2011).

The resident's fertility behavior was restricted by the one child urban family planning system; meanwhile, the traditional concept of son preference still exists in their minds. Interviewees Wang Mei and Li Jing lived in a village-turned-community near the county seat in the south of Henan province. Their community changed from a village into a city community due to urban development, and so villagers became urban residents, and their fertility behavior had to comply with the provisions of the urban family planning policy. This meant that they no longer enjoyed the interval two-child policy in place for rural villagers. The majority of men in the community were informally employed in the construction industry or worked as porters. Wang Mei and Li Jing occasionally did casual jobs, such as working in a nearby shoe factory or helping people 
wash cars in the street, but most of the time they stayed at home doing their own housework.

Wang Mei was born in 1966, married at 22, and shortly after gave birth to a daughter. When she gave birth to her son in 2005, her daughter was already 19 years old. In order to avoid paying the family planning fine, she and her husband got divorced but still lived together. After their son was born, the two did not remarry due to their fear of cumbersome procedures and family planning penalties. Li Jing was born in 1970. She was married once before and then rebuilt a new family with her current husband. Now, there are four people in her family: Li Jing, her husband, their son Xiaoyu, and stepdaughter Qingqing (the daughter of her husband and his former wife). The main income for this household consists of the wages of her husband and her stepdaughter. Li Jing conceived a girl before their son was born, but in the 9th month of her pregnancy, the family planning department forced her to undergo induced labor for failing to apply for a second-child birth certificate. Four years later, in 2006, when her son Xiaoyu was born, the family paid 8000 yuan in social compensation fee and her husband was punished by his danwei because of the son's birth. Wang Mei and Li Jing reside in a community with 1005 households and a population of more than 3200 . According to a rough estimate from family planning cadres, among the 45-50-year-old females of similar age to Li Jing and Wang Mei and whose first child was a girl, about $70 \%$ of them had a second child. In accordance with the requirements of the family planning department, the social compensation fee for a child is around 10 thousand yuan. By looking for alternative ways such as guanxi (personal connections), offering feasts, and presenting gifts, the amount that residents actually paid was between 8000 9000 yuan. This is an affordable cost for the average family in the community, making it possible for families in the community whose firstborn is a girl to have a high probability of having a second child.

It is not uncommon in the village-turned-community for individuals to have experiences similar to those of Wang Mei and Li Jing. Here, the culture of family and the neighborhood that surrounded them intertwined with the modern institution to create a unique situation. On the one hand, the community network of family and neighborhood abide by the traditional fertility culture; on the other hand, relevant departments representing institutional norms vigorously promoted the family planning policy. Opposing the former would lead to exclusion from family, while opposing the latter would lead to punishment from the government. When culture encountered institution, the process of interwoven interaction and contention constantly influenced and shaped families' fertility choices. In any case, in the context of such communities, when making a choice between cultural and institutional balance, they will tilt more to the cultural side.

When institution and culture collide, fertility decisions comply with traditional cultural norms to meet the fertility bottom line

Zhen and Junjie (1997) proposed that rural fertility culture possesses a "boundary" nature, and farmers have an insurmountable cultural boundary of fertility-that is, giving birth to a son.

Gender is the primary determinant of farmers' fertility needs. The second determinant is the number of children and timing of births-early birth is for having a son, more births is also for having a son (Chen and Guangzong 1996). Understanding the 
boundary nature of farmers' fertility culture has an important reference function for determining the childbirth policy. Some researchers put forward the concept of "bottom line of life" to emphasize the son preference in farmers' fertility behavior and suggest that farmers' fertility bottom line is composed of long-term economic and social factors, which existed before the implementation of the family planning policy. When the policy limits the number of births, the fertility bottom line of son preference is thus highlighted (Chen 2013). Ogburn also points out that in the process of social change, the speed of cultural change lags behind institutional change (Zhen and Junjie 1997).

In the interviews for this study, it was clear that for Wang Mei, "giving birth to a son" was a behavior aimed to meet the fertility bottom line. From interviewee Li Jing's birth experience, it can be seen that "having one's own child" is the fertility bottom line for divorced families.

I was thinking of remarrying as husband and wife. First of all you need to have a (common) child, without children, there will be a lack of foundation of emotion, thus the affection is not solid enough. I know a lot of remarried couple friends, just because of the children, the couple used to have a good affection, later on it turned to bad. (Interviewee Li Jing)

In strong institution and strong culture communities, when cultural demand conflicts with institutional demand, the institution gives way to culture. When the family planning system touches people's fertility bottom line and reduces the possibility of giving birth to a boy, people tend to use various illegal or irregular gaming means to maintain their fertility bottom line. In a study of the implementation of family planning system in Chen Village, Xinxiang (2004) sums up eight methods used by farmers to maintain their own fertility bottom line: deceit (such as having the first child declared to be disabled to qualify for having a second child), seeking personal connections, physical protest, monetary bribery, escape, hidden marriage, false divorce, using medical technology to diagnose fetal sex, and shielding each other in community. This interview also yielded a similar example when interviewee Li Jing described that one of her neighbors had had a second child by using the above methods.

We have a neighbor who wanted to have a second child. She declared the first child to have a disability, paid two or three thousand yuan, bought a new birth certificate, even though the first-born child did not have disability. (Interviewee Wang Mei)

Interviewee Wang Mei used the method of false divorce to have her second child, achieving her and her husband's desire to have a boy.

At that time I heard people were talking about a lot of fake divorces. We had a discussion, planned to do the same, falsify a divorce, and see what next to do after the second child is born. I did not agree at the beginning, afraid that we would end up with a real one, but if didn't falsify the divorce, a pregnancy test would have to be done, and it would be terrible if the inspectors finds out. We started quarreling and fighting every day, so that everyone thought that two of us couldn't maintain a 
family anymore. After a few days, I left, went back to my parents' home, and the people in the neighborhood sincerely believed that we had divorced, so they all felt great pity for us. After two or three days, I quietly snuck back, staying at home and not going outside; my husband went out for work.

I only went out quietly after dark, to have a little walk around, thinking, if you hide at home the whole time every day, you would feel annoyed as well. If I heard a sign of trouble, I felt terrified. Until childbirth, nine months later, when I gave birth to a boy, then people realized that we were falsely divorced. They sent gifts and congratulated us a lot, (the person who is in charge of) family planning was not happy with it. They came to our house, but we were divorced, and we didn't work for any danwei. We said that the child had already been born, and if you want to take him away then just take him away, or you can impose fine on us, meanwhile, we don't have much money to pay for it. Finally, we sought some personal connections, paid fines of several thousand yuan, registered the child's residence under our household, and finally we resolved this matter. (Interviewee Wang Mei)

From Wang Mei's case, it is not difficult to see that in the social context, when institution and culture collide, people tend to comply with culture and resist institution. Of course, most of this resistance was not an open violent confrontation, but used a tortuous way to impact the institution, using a variety of so-called "weapons of the weak" (Scott 2011). In this way, they not only guarded the fertility bottom line, but also did not break the institutional kernel; therefore, these methods are deemed to be expedient measures in special situations. Zongzhi (2001) also pointed out through his study on the Qing Dynasty litigation data that folk custom and practice differ from official legal institutions. In the process of the formal institution's implementation, there often exists a "decoupling of expression and practice."

\section{Traditional fertility culture norms are achieved through "shared reality" of members}

Existing studies have pointed out that the characteristics of traditional rural communities still preserve the cultural norms and conceptual awareness of village-turnedcommunity residents (Wu 2011). As Li Yinhe suggested, "village" as a traditional rural community has special features of "sharing information," "limited scope of activities," and "lesser mobility"; villager behavior has the characteristics of "competitiveness, convergence, conformity," etc. The impact of traditional fertility culture is actually obtained through interaction between members, such as learning from, imitation of, and recognition of others. In the social psychological study of culture, the concepts of "shared reality theory" and "intersubjective consensus" point out that the perception of attitude and behavior of others is the intermediary mechanism by which cultural norms affect individual behavior (Higgins 1992; Wan and Chiu 2009; Wu and Yang 2013).

In traditional rural communities, "others" in the village refer to the husband, husband's siblings, parents-in-law, sisters-in-law, distant relations, and neighbors. Some studies analyze the process by which the son preference as a cultural consensus has been internalized or reproduced by family members (Weidong and Zijuan 2012). As interviewee Wang Mei described the process of giving birth to her son, it can be seen that her fertility decisions were also affected by the perception of other members of the 
community: one is the neighbors' fertility concept of son preference; the other is her husband's son preference.

One neighbor, her first child was a girl, also 19 years old, she wanted to have another child and got pregnant. She found that it was a girl again, then she had an abortion. She got pregnant one more time, it was still a girl. She had no choice but to give birth, and by now the second girl is around 5 or 6 years old. She and her husband fight every day. He scolds (and curses) her for not having a boy, but she can only stay silent.

My husband said, "Let's have another child too." At first I did not agree, but later on, a neighbor living next door to us had a second child and that was so ideal. The neighbor said to me, "You should have one more child, how lonely if there is only one child. If you have another one, the two can be good companions, look at my case." Hearing this, I changed my mind, went together with the neighbor and removed the contraceptive ring secretly. She told me that she couldn't be pregnant for a long time after removing the ring, so I did not take it seriously, until one day I suddenly found myself pregnant. Then I started to panic, and asked my husband how to deal with it. He answered we should keep the child since I was already pregnant. If it's a boy, I can have old hen soup ${ }^{2}$ as much as I like; if it's a girl, then there will be nothing. I also saw another neighbor, after having a son her voice would be different than before, with more tough tones. (Interviewee Wang Mei)

According to interviewee Li Jing's story, the purpose of giving birth to her second child is to have a child with her current husband. Li Jing's decision was also influenced by the ideas of other members in the community, such as pressure from her younger sister-in-law.

The second aunt of my child said to others, without having a child with my husband, I don't have the right to speak in my husband's big family. We are remarried couples, unlike others who are in the first marriage. (Interviewee Li Jing)

Wang Mei and Li Jing represent the situation of the majority of female peers in their community who are of similar age: not having regular work, economically dependent on the family, and remaining in an economically weak position. Furthermore, because the pension institution is imperfect, these women choose to "bring up sons" to "provide for their old age." The family planning system limited the number of possible births, but did not develop a supporting institution to meet the individual's needs in their old age. In the cases of Wang Mei and Li Jing, the traditional culture of having a son meets the individual's actual demand, when exogenous institution conflicts with endogenous cultural demands, the individual will inevitably choose to abide by the community culture, regardless of the violation of institutional rules. On the other hand, culture, as norms constructed in human practices, has a functional role in satisfying the needs of its members. When the individual faces a loss in the future or in uncertainty, culture can provide reference frame and criteria for behavior and decision-making to meet the individual's preferences, rather than the intangible imperatives that govern individual behavior. In this sense, culture has a certain functional significance for its members. 
Cialdini et al. (1990) divide the norms into 2 category: despriciptive norms and injunctive norms. Descriptive norms refer to the shared behavioral choices which are perceived by individuals; injunctive norms are the formal rules or rules written on paper. Morris et al. (2015) further point out that endogenous local cultures are similar to descriptive norms, while acquired institution and policy are similar to injunctive norms. In the early stages of social change, descriptive norms have greater influence on individual behavior and thus often are used by individuals as a frame of reference for their actions. Individuals also use a "social autopilot" as a metaphor to describe the guiding function of the local shared culture on personal behavior. The same consensus exists in the study of neo-institutional sociology. For instance, in the classic study by Meyer and Rowan (1978) of educational organizations, they point out that the effectiveness of implementing change in an institution depends on whether the change satisfies people's internal functional needs. When the implementation within the institution collides with endogenous culture as it meets individual needs, the execution is at its worst, even if the institution is perfectly designed, it will be of no avail. For the institution of danwei, consisting of communities of "strong institution and weak culture," which will be discussed next, we will see how exogenous institution reshapes the new fertility culture by changing the individual's functional requirements, thereby strongly institutionalizing the implementation of the fertility institution.

\section{Women's fertility choices in strong institution and weak culture communities}

In urban communities, especially danwei communities, people's fertility decisions are strongly constrained by the family planning system and weakly influenced by traditional cultural norms. The authors select a maternity case that occurred in a danwei community and observe the interaction between institution and culture, as well as the process of how institution and culture affect the female's fertility decision-making. Some scholars have pointed out that a danwei community is a unique type in the social development of China, for that it has strong institutional characteristics in resource allocation, social management, and welfare supports (Lulu 2002). In such a community environment dominated by an institution, the female's fertility decision-making is severely restricted. On the other hand, the fertility culture of danwei communities is completely different from traditional rural communities, since the latter is constructed bottom-up by community members from the shared concept and the code of the fertility culture, while the former is passively formed in the process of the governor's topdown advocacy and strong implementation.

\section{The danwei community environment}

In a danwei community in the Inner Mongolia Autonomous Region, where interviewee Tong Ling lives, the fertility concept of "fewer births, late childbearing" and "one-child glory" is accepted and recognized through administrative mobilization and advocacy. It furthermore becomes the progressive values being pursued. The new fertility culture has been reconstructed along with the implementation of family planning policy. Tong Ling was born in 1963, worked in a state-owned tree farm for a long time, used to work as a typist, and was secretary of the Communist Youth League. She had always been an outstanding employee at work. In 1987, she gave birth to a son. Tong Ling is Han nationality, but because she wanted a second child, she changed her ethnic status to 
Manchu so that she could be permitted to have a second child. Despite this change, environmental constraints from her danwei and pursuit of her career eventually led her to give up the chance to have a second child.

It can also be seen from Tong Ling's words that fertility culture was changing in danwei communities through the advocacy, implementation, and promotion of fertility policy. After the family planning policy was gradually introduced, the fertility culture changed from "sons and daughters" at beginning into one-child glory.

Before 1980, my big brother had two sons. The concept at that time was "more sons, more happiness". Meanwhile, people wanted to have both sons and daughters.

According to the rules of the tree farms there, when someone's daughter or son got married, the young couple's bedclothes had to be hand made by the families who had both has sons and daughters. Families without both a son and a daughter, even if they had a dozen children, still could not qualify to do this. Everyone there hoped that the new couple would have sons and daughters, full of happiness. My eldest brother particularly wanted a daughter, and he tried to have a third child. As expected, it was a girl. At last his long-cherished wish was fulfilled. But my eldest brother still got a little frustrated: his danwei reduced one level of his wage, and asked him to make a self-examination and to share his criticism with the whole danwei. (Interviewee Tong Ling)

\section{Institution-changed fertility culture: from sons and daughters to one-child glory}

Cultural changes in terms of concepts and norms lag among cultural changes at institutional and physical levels (Zhang and Peng 2015; Ogburm 1951). An earlier study on the strong-strong type of community found that when institutional demands collide with cultural demands, institutional regulations gave way to cultural norms. In a particular social governance environment, when the cultural norms need to be changed throughout the institution, a relevant institutional system will be developed, to assist in changing cultural concepts and regularizing personal behavior. This practice is more common in danwei organizations. The same process is also found in Tong Ling's narrative. In danwei communities, the implementation of the one-child policy depends on two related institutions: one is the institution of penalties and the other is institution of rewards and benefits. When Tong Ling's eldest brother had his third child, his wages were downgraded by the danwei and he "did self-examination and informed criticism." Tong Ling's third sister also violated the provisions of the danwei and had her second child in 1984. After that, she was dismissed from the office, her cadre status was removed, and a notice about the change in her status was broadcast continuously for a month throughout the forest bureau branch offices.

My third sister didn't take it seriously when she was pregnant, and she and her husband worked normally every day. Finally her son was born, and he was a big fat baby, and their desire to have a son was finally satisfied. It so happened that her son was born in the month which happened to be the month of family planning campaign. My third sister was a teacher at a primary school, had cadre status, and even though she was a cadre she violated the policy. So it clearly was not a good example. The forestry bureau decided to impose a fine immediately, dismissed her from the office, 
removed her cadre status, and she finally lost her job. After that, the criticism was issued throughout the entire forestry bureau, with loudspeaker broadcasting this resolution for a month. At that time, not only this tree farm, but all the tree farms of the forestry bureau had loudspeakers, and its sound was extremely loud, so when it started, every household of all the tree farms could hear clearly. Then after one month, my third sister became a bad example for everyone.(Interviewee Tong Ling)

In addition to the penalties for fertility behavior that violates institutional rules, the danwei also set up corresponding incentive institutions and individual welfare institutions to ease the implementation of the family planning system. For example, Tong Ling's danwei provided women who had a one-child certificate with a maternity allowance, six months' maternity leave, and access to nurseries that could help raise their children. Meanwhile, through setting up a typical example and encouraging work first, the community created an atmosphere of one-child glory culture.

Now in retrospect, for many years I actually had little energy and time to take care of my son, so it is impossible to give a second child. In those years when engaged in youth league work, young people were asked to be positive and progressive, to respond to the family planning policy, to make a contribution to the "Four Modernizations". I took the lead to get a one-child certificate, to put on a contraceptive ring, and to give up the chance to have a second child.

There were a lot of benefits after receiving the one-child certificate. All medical expenses in the hospital would be reimbursed, with extra subsidies and six months' maternity leave. Altogether there were more than 300 workers in my danwei, and more than 200 were women, and we all received one-child certificates. We were quite indifferent about having a second child, even those Mongolian colleagues who could have a second child just like me, also applied for one-child certificate. Every year anyone who received a one-child certificate would receive something, from both (my) danwei and my husband's danwei.

Although I could rest for half a year after receiving the certificate, indeed I didn't rest that long, and after only 50 or more days I returned to work. At that time the nurseries at the danwei were free, leaving children inside, so parents can focus on theirwork. In my case, my child did not make too much trouble for me. I've been busy working, with no leisure time. Whoever in the danwei gave birth to a child, with her consent, we'd immediately help her to apply for a one-child certificate, and under normal circumstances no one opposes it. I was in charge of family planning in the danwei for more than 10 years, and no policy violation ever occurred. Whoever violate the policy would certainly lose her job, party members would be expelled, and youth league members would be expelled, so at that time everyone was very motivated, and since it was very hard to get into the Party, no one could really stand such a sanction of being expelled from the Party. (Interviewee Tong Ling)

\section{The change of birth culture: from strong execution by institution to the internalization of the new birth cultural norms}

Yusheng (2009) points out that when an institution is consistent in its cultural norms, the institution has the greatest influence on people, the institution's organizational 
performance is strongest, and this performance relies on individual's subjective recognition and acceptance to the institution. In danwei communities, a birth culture of onechild glory has been constructed, according to the demands of the family planning system. The institution's impact on female fertility behavior no longer relies on imposing external forces, but automatically is formed through the internalization and acquisition of cultural norms. In danwei community, the process of institutionalization gradually shapes the fertility culture, influencing and changing individual's birth concept and choice, as can be seen in the course of fertility of Tong Ling and her six brothers and sisters (see Table 1).

Tong Ling's siblings all worked in subordinate danwei of the forestry bureau in the Inner Mongolia Autonomous Region. Tong Ling's eldest brother worked on a tree farm. Her eldest sister worked in a diesel engine plant. Her second and third sisters worked in elementary schools. Tong Ling worked on a tree farm, and her younger sister and brother worked in other subordinate danwei of the forestry bureau. These danwei have unified management and similar institutions, and the living pattern and community culture are all similar to each other. From the change of Tongling's siblings' fertility choices, it can be seen that the fertility institution reshaped the fertility culture and, at the same time, individual's fertility decision were gradually disciplined by the environment of strong institution and weak culture communities.

Tong Ling's eldest sister wanted a second child in 1983, but unfortunately, the family planning policy began to be strictly enforced. In spite of this, the sister found a way to change the ethnic identity of her household register from Han to Manchu. Tong Ling's second sister benefited from "changing the household registry" to become a Manchu, successfully circumventing policy restrictions and subsequently giving birth to a second child. In 1984, the family planning policy was strictly implemented in their locality, and Tong Ling's third sister was punished because her husband insisted that she should not change her ethnic identity. After giving birth to the second child, she was expelled from public office, lost her job as a teacher. In 1987, Tong Ling gave birth to her son, though

Table 1 The changing process of fertility choices in danwei communities

\begin{tabular}{|c|c|c|}
\hline End-year of fertility & Family members & Fertility status \\
\hline 1980 & Eldest brother & $\begin{array}{l}\text { She has two sons and changed her ethnic identity from Han to Manchu } \\
\text { to give birth to the second child. }\end{array}$ \\
\hline 1983 & Eldest sister & $\begin{array}{l}\text { She has two sons and changed her ethnic identity from Han to Manchu } \\
\text { to give birth to the second child. }\end{array}$ \\
\hline 1983 & Second sister & $\begin{array}{l}\text { She has one son and one daughter, whereas the daughter is the second } \\
\text { child. She changed her ethnic identity from Han to Manchu, to avoid } \\
\text { the penalty }\end{array}$ \\
\hline 1984 & Third sister & $\begin{array}{l}\text { She has one daughter and one son, whereas the son is the second child. } \\
\text { She has not changed her ethnic identity. After her son was born in 1984, } \\
\text { she suffered punishment by her danwei and was dismissed from office, } \\
\text { lost job. }\end{array}$ \\
\hline 1987 & Tong Ling & $\begin{array}{l}\text { She has only one son and changed her ethnic identity from Han to } \\
\text { Manchu in order to have a second child. Due to work demands and the } \\
\text { one-child atmosphere in her danwei, she ultimately did not have second } \\
\text { child }\end{array}$ \\
\hline 1989 & Younger sister & $\begin{array}{l}\text { She has one child and did not want a second child or change ethnic } \\
\text { identity. }\end{array}$ \\
\hline 2001 & Younger brother & $\begin{array}{l}\text { He has one child at later age. Before the child was born, his wife aborted } \\
\text { twins for the pursuit of education and career. }\end{array}$ \\
\hline
\end{tabular}


as a Manchu she is allowed to have second child and she wanted to, but for the pursuit of her career she did not have a second one. When it was Tong Ling's younger sister's turn, she did not want a second child at all, nor did she want to change her ethnicity change to Manchu. Tong Ling's 5-year-younger brother and his wife for the pursuit of higher education and career, decided to abort their twins. His child was born later after the couple felt ready for parenthood. Tong Ling called the fertility case of her younger brother "the real family planning."

In summary, in danwei communities, along with the advantageous supplementary institutional welfare, the family planning policy has been strongly carried out with strict administrative rewards and punishments. The fertility culture was gradually reconstructed during the institution's implementation, from the need to have "both sons and daughters" to the one-child glory. Changes in the fertility decisions of Tong Ling's seven siblings demonstrate that cultural change is a gradual process, lagging behind the institutional change. When the community culture changes and is reconstructed according to institutional demands, the cultural and institutional forces have the strongest constraint on individual behavior.

\section{Women's fertility choices in weak institution and strong culture communities}

In recent years, with the transfer of the rural labor to the city, emigration has become an important impetus to farmers' migration and flow. The mass exodus of labor has turned rural communities into "empty shells" and gradually changed people's fertility choices. In the context of labor mobility, the effect of the fertility institution and traditional birth culture on rural women's fertility decision-making shows a new trend. Interviews show that the family planning system gradually relaxes its constraints on the number of births, but the son preference is still the basic fertility bottom line that most people seek. It is worth noting that with the improvement in family economic level brought about by out-migration has led to an increase in the number of births. In the following part, we will take Hewan Village in Henan Province and Baofeng Village in Inner Mongolia Autonomous Region as examples, in order to contrast and analyze how institution and culture impact fertility. In addition, rural women's experience with fertility in other areas (such as in Hebei Province and Shanxi Province) will be also used as a supporting evidence.

Weak institution and strong culture: rural communities in the context of population mobility Interviewee Tian Xue lives in Baofeng Village, which is located in a poverty-stricken county in southeastern Inner Mongolia. Although this village is on the outskirts of the county, it is still a traditional poor village in a poor county. The village is located at the junction of farming and pastoral areas and has a harsh geographical environment, with a total population of about 4080, while nearly 1200 of them are long-term emigrants. The main economic income of the village is based on agriculture, livestock breeding, and young migrants' wage incomes. Most young adults work in the mineral enterprises in the county or surrounding areas; some work in the service industry in the county as vegetable vendors, taxi drivers, restaurant owners, or else. The village has a large arable land per capita, 7.1 acres. However, the land is barren with low grain output, yielding only about $300 \mathrm{~kg}$ of wheat per $\mathrm{mu}\left(1 \mathrm{mu} \approx 667 \mathrm{~m}^{2}\right)$. 
Meanwhile, due to the location in a non-pastoral area, in accordance with government regulations, the only sheep that can be raised in the village must be through captive breeding; the stock breeding industry requires great input, and the return is quite low. Tian Xue, 34, is married. Her husband works in a nearby copper mine and has a monthly income of close to 4000 yuan. The couple rents a house in a county town. Their 9-year-old son lives with them and studies in the county town's elementary school. Tian Xue stays at home to care for the child.

Most of her peers in the village are working in the county town, with fewer working in nearby cities or developed coastal areas. Their income can only maintain a basic living. Tian Xue's neighbor runs a food stall in the county town; that couple has only one son, who studies in the local elementary school. According to the village cadre's estimation, $80 \%$ of families in Baofeng Village whose firstborn child is a boy do not have a second child; most families with a girl as the first child, however, have a second child, and some families even have a third child in order to give birth to a boy.

Interviewee $\mathrm{Wu}$ Lan and Qi Yu live in Hewan Village, which is located in the southeast part of Henan Province, with a total village population of 2865 , with around 750 perennial emigrants. The village's per capita arable land is $2.3 \mathrm{mu}$. The traditional source of income used to be from agriculture, but in recent years, household incomes mostly come from out-migration. Young adult out-migration from the village mainly means working in factories in Guangdong, Jiangxi, and Fujian, with a monthly income of between 5000 and 6000 yuan. Some young adults run an agricultural harvesting business, and their annual income is about 80 to 100 thousand yuan. Hewan Village has a better family economic condition than Baofeng Village, so most women of childbearing age of Hewan Village have two or more children, and most families have a second child when their firstborn child is a boy. Interviewee Wu Lan is 31 years old, and her husband works in a tannery in Guangdong Province. Wu Lan follows her husband to work in a supermarket in Guangdong Province, and their total monthly income is nearly 8000 yuan.

They have two sons: one is 9 years old, while the other is 6 years old. Both boys are taken care of by her parents-in-law whose are aged slightly over 50. During the slack season, her father-in-law temporarily works at construction sites in a nearby city; their total family income is relatively self-sufficient. Twenty-nine-year-old interviewee Qi Yu lives in the same village. Qi's husband and father-in-law work in a ceramics factory in Jiangxi Province. They are both professional technicians, and the father-in-law is in a management position. Their total monthly income can reach 20,000 yuan, so they are comparatively well-off. Qi Yu and her mother-in-law stay at home to take care of two sons, a 3-year-old and a 1-year-old.

By comparing the Baofeng Village and Hewan Village, we find that the factors affecting villagers' fertility behavior of these two villages are similar. First, the fertility decisions of people living in rural areas are influenced by the traditional fertility culture of son preference. It can be seen from the case of Baofeng Village in Inner Mongolia that people are not willing to have a second child if the first one is a boy. However, if the first child is a girl, they intend to have a second child. Similarly, families in Hewan Village in Henan want to ensure that the family has a boy; the difference is that for most families, even if the family has a boy as the first child, they will continue to try and have a second child. Second, comparing the cases of the two villages, we find that 
the impact of the family planning system is gradually declining. The interval two-child policy provides families who have a girl as the first child with the opportunity to have a second child. In most communities, the family planning policy was not strictly enforced, such as in Hewan Village, many families' firstborn child was a boy, and they later gave birth to a second child after symbolically paying a "social maintenance fee." The social maintenance fee paid by Hewan villagers was around 7000 to 10,000 yuan, much less than the amount specified by the family planning department, so many families could afford it. A similar situation was also found in other interview cases in other regions. Interviewee Yufang, who lived in a rural area of Hebei Province, said, "The policy has regulated that if the first one is a boy, then we are not allowed to have a second child. But here the policy has not been carried out strictly, and every family just pays some money, and then has another child." Interviewee Xiaomiao in a rural area of Shanxi Province also mentioned that "in our village the family planning policy was not so strict in recent years-just pay some money, then the problem will be solved."

After meeting the bottom line of "giving birth a boy," the economic level will determine the number of birth. Comparing the case of Baofeng Village and Hewan Village, we find that after meeting the bottom line of fertility culture, family's economic condition is the next important factor that determines people's choice of number of births. For example, in Baofeng Village, land revenue and out-migration income are not high and most families choose not to have a second child if the first one is a boy, or if the first child is girl, then they'll expect the second child to be a boy. In Hewan Village, in contrast, since most families' out-migration income and land income are relatively high, even if the first child is a boy, economically well-off families who have adequate economic capacity and manpower to look after the child will have a second one. Income level determines the number of births after meeting the fertility bottom line, and this can also be corroborated in other interview cases, such as Zhou Lan in southwest Anhui Province, whose husband is a "live-in son-in-law." According to the local family planning system, they can have a second child even if the firstborn is a son. They have a 7-year-old son and just gave birth to a girl in the past spring. The two children were born 7 years apart. The decision to have a second child was made after the family's economic condition improved, and the income from years of outmigration enable "the family to build a two-story house, buy a car, build a garage, and become comparatively well-off."

In short, in the current environment of large population flow, a new situation has emerged in rural communities. Institutional fertility constraints have been reduced, the son preference culture continues, and culture becomes a major factor determining the female's fertility behaviors. The incomes of the emigrants enhance their families' economic level, while the economy condition is an important factor determining "how many children" to have, besides having a son. This conclusion has also been verified by the "little second child" phenomenon, appearing in the current rural communities, with a long interval existing between the firstborn and second child. Little second child refers to the phenomenon that many rural families decide to have a second child many years after the firstborn child. According to relevant research and analysis, this is a common result of increased family economic level and weakened enforcement of the family planning system (Xinhua 2012). 
The family's economic condition has caused female fertility choices to become divided. If there is more income and the family's economic condition is good, then people want to have a second child even if the firstborn is a boy; if the family is in poor economic condition, for whom the "one child is still unaffordable," the couple will no longer want to have a second child. In addition, the female fertility status is also affected by other factors, such as the willingness to move into the city, women's health condition, and whether the grand parents can look after children, but these are merely individual factors. Overall, the fertility choices of women are still unable to escape from the shackles of the community culture, in their respective communities, and they still need to meet the requirements of community culture for the son preference. At the same time, being relatively well-off financially has become an important condition allowing the couples to go beyond institutional limits and the son preference culture.

\section{Conclusion}

Fertility is related to all aspects of people's lives, such as marital relationship, marital quality, pension expectation, educational investment, and daily life maintenance. Since 1980, China has been implementing the family planning policies, with institutions and culture as two social constraints. People are obliged to make rational decisions and carefully evaluate the results of their fertility choices. For people, the family planning system is an exogenous norm, unlike the cultural norms long-established in the community. In contrast, the traditional fertility culture is a naturally formed endogenous norm, and its disciplinary nature, aspirations, and values are built on people's behavior and thus better fit people's demand. In an uncertain context, it can be regarded as a reference for people's behavior.

This paper identifies four "institution-culture" types and details the interactive process of their impact on individual behaviors. When the demands of policy and institution conflict with the demands of the cultural norms, people resort to various weapons of the weak to prioritize how they will meet the cultural demands, through maneuvers, negotiation, and a mutual construction with the institution to avoid institutional constraints, guard the cultural boundaries, and comply with their fertility bottom line. For example, the choices of "seeking for Guanxi," "running away," "false divorce," "hidden marriage," "violent resistance", etc., are made to avoid punishment from the family planning system. These behaviors can be found in the first scenario of strong institution and strong culture type. In the second scenario, when the institution is too strong, and there are a series of supporting institutions to regulate the individual behaviors, and fulfill or compensate the functional role of the original culture, the original cultural norms of the community will be reset and replaced and a new community culture will be formed in accordance with institution's demands. As for the strong institution and weak culture type, the danwei communities enforce a reward and penalty system to implement the family planning system, so that the fertility culture of the community undergo the change from having both sons and daughters to the one-child glory. In the third case, the institutional power gradually declines, and the power and function of the community culture still exist. An improvement of the family's economic condition helps the individuals and families to overcome the institutional limits to meet the cultural requirements. This situation is an example of the weak institution and strong culture type. Most rural communities with labor migration belong to this type. 
The farmer's income help increase the overall household income, so the punishment fee for having "illegal" children can be paid, and thus, the community cultural norm of son preference becomes possible. In the fourth case of weak institution and weak culture, the individuals' fertility choices saw the trend of individualization. This type is less relevant to the topic and thus not further addressed.

Studies of the institution-culture interaction can often be found in organizational sociology, cultural sociology, and China studies. As an example, Yusheng (2009) points out that when the demands of institutional norms collide with the demands of cultural norms, organizational performance is at its lowest and the execution cost of the institution is at its highest. Meyer and Rowan $(1977,1978)$ study the modern organizational performance from the perspective of the new institutionalism, and the "culturalism" in China studies around the world also emphasize the particularity of the Chinese society and culture (Yingying 2012).The various perspectives of these studies have made different contributions to our understanding of the relationship between institution and culture. On the basis of the above theory, this paper further advances and extends the study of individuals' micro-behavior in cultural and social psychology (Chiu and Hong 2011; Morris et al. 2015), with an attempt to explore the interaction among institutions, culture, and individual behavior. We see institution as an exogenous, prescriptive norm and culture as an endogenous, descriptive norm. Together, the two have a binding effect on individual behavior, and when the two norms appear simultaneously, however with difference sources and effectiveness, they influence how individuals make choices and decisions. In this paper, we describe a detailed interaction process of the institutional, cultural, and individual behavior through different community cases, and we analyze the interaction process. This is one of the theoretical contributions of this paper.

In addition, we also discuss culture's influence on institutional changes of China. Since the Reform and Opening-up in 1978, the Chinese society has experienced frequent institutional transformations and policy changes over nearly 40 years of development. China provides abundant opportunities for sociologists to observe and research (Yang and Litao 1996; Liping 2005). Social science research on the institutional changes in China is relatively abundant, such as research on the expert participation mode in social policy changes (Zhu 2011), research on changes of China's petition system (Shizheng 2012), the "danwei system" study (Lulu 2002), and study on the changes of China's ethnic policy (Binghao 2009; $\mathrm{Hu}$ and $\mathrm{Hu}$ 2011). Through research on the interaction of the fertility culture and institutions in various communities, it can be found that the institutional implementation influences and constrains the community culture from the stages of policy making to execution. Therefore, it is important to examine institutional changes and effectiveness while considering cultural factors. Past studies of policy and institution changes rarely consider culture as an independent element.

In fact, culture, as norms constructed in the course of people's behavior, exists with indifferent levels of the organization (such as a household, formal organization, village, community, state) and has different effects on personal behavior choices along with formal institution (Lu 2015).Research on cultural factors has practical significance in policy making and policy implementation, such as examining whether the new policy is in accordance with the demands of the local culture and when they are not in 
agreement, determining how to establish a new culture to assist with the implementation of the new policy. In this sense, the four classifications of various relations between institution and culture in this study may also serve as an important reference for analyzing other policy implementations.

This paper also has its limitations, such as the analysis used cannot cover the behaviors of all individuals in the community and thus cannot fully represent people's diverse original fertility choices. In addition, the paper tries to combine theories and perspectives from a multi-disciplinary research of demography, organizational sociology, and social psychology. However, limited by interview data, the analysis of the processes for individuals to make fertility choices under cultural and institutional restrictions are still not as complete as it hopes to be. Other research methods, such as experiments and social survey, can further supplement the findings.

\section{Endnotes}

${ }^{1}$ See China National Radio Website, China's fertility policy inventory, interviewed Jul 1, 2015 (http://news.cnr.cn/special/sy/pd/201311/t20131107_514065149.shtml).

${ }^{2}$ In China, old hen soup is a popular and nutritious diet for pregnant women.

Authors' contributions

WY finished most of case interview study and writing of the paper and drafted the manuscript. YY-y finished the analysis of some interview cases and amended the paper. WX-j amended the manuscript. CE finished some case interview. All authors read and approved the final manuscript.

\section{Ethics approval and consent to participate}

The publication of these interviews in paper has got verbal consent from the participants.

Competing interests

The authors declare that they have no competing interests.

\section{Publisher's Note}

Springer Nature remains neutral with regard to jurisdictional claims in published maps and institutional affiliations.

\section{Author details}

${ }^{1}$ School of Ethnology and Sociology, Minzu University of China, Beijing, China. ${ }^{2}$ Institute of Sociology, Chinese Academy of Social Sciences, Beijing, China. ${ }^{3}$ Party School of Hainan Provincial Committee of C.P.C, Haikou, China.

Received: 21 April 2017 Accepted: 19 June 2017

Published online: 29 June 2017

References

Becker, GS. 1987. An Economic Analysis of Fertility Control the Development of Population Economy. Beijing: Peking University Press.

Benfeng, Du, and Qi Jingjing. 2011. Review and Look Forward for Population Policy in China: Based on Public Policy Cycle Theory Visual Angle. Northwest Population Journal 3: 1-10.

Chen, En. 2013. Restructure the Relationship between Country and Farmer-The Family Planning History of Two Villages in H County: 1979-2009. Thesis for PhD in Social Relations, Graduate School of Chinese Academy of Social Sciences.

Chen, Junjie, and Mu Guangzong. 1996. Structure of Fertility Demands of the Chinese Peasants. Social Science in China 2: $126-137$.

Chen, Caixia, and Yuan Zhang Chun. 2003. An Empirical Study of Contemporary Rural Female's Fertility Behavior and Fertility Desire. "Population and Economics 5: 76-80.

Chiu, Chi-yue, and Ying-yi Hong. 2011. "Social Psychology of Culture", Liu Shuang (Trans.). Beijing: China Renmin University Press.

Chunyuan, Zhang. 2000. Evolution of Chinese Fertility Regulation Policies since 1949. Market \&Demographic Analysis 1: 48-55.

Cialdini, RB, RR Reno, and CA Kallgren. 1990. A Focus Theory of Normative Conduct: Recycling the Concept of Norms to Reduce Littering in Public Places". Journal of Personality and Social Psychology 58: 1015-1026.

Fei, Xiaotong. 2009. "China's Gentry", Zhao Xudong, Qin Zhijie (Trans.). Beijing: SDX Joint Publishing Company.

Guangzong, Mu. 2000. The Modernization of Fertility Culture and the Change of Birth Control Mechanisms. Chinese Journal of Population Science 3: 23-30. 
Guangzong, Mu, and Chen Wei. 1995. Summary of the Symposium on New Population Problems and Countermeasures in the Second Drop of China's Fertility Rate. Population Research 5: 54-63.

Hehui, Jin. 1995. A study of Rural Women's Decision-Making Power on Reproduction and Fertility. Chinese Journal of Population Science 1: 33-44.

Higgins, ET. 1992. Achieving 'Shared Reality' in the Communication Game: A Social Action That Create; Meaning. Journal of Language and Social Psychology 11: 107-131.

Hu, Jing. 2010. Income, Comparative Position and Women's Fertility Desires. South China Population 4: 3-9.

Hu, Angang, and Lianhe Hu. 2011. The Second-Generation Ethnic Policy: Toward Integrated Ethnic Fusion and Prosperity. Journal of Xinjiang Normal University (Edition of Philosophy and Social Sciences) 5: 1-12.

Hu, Ping, and Chuzhu Zhu. 1996. Debate on Family Planning and The Change of Chinese Women's Life. Chinese Journal of Population Science 4: 21-26.

Jin, Binghao. 2009. "Development of 60 Years on the National Policy of New China". Journal of South-Central University for Nationalities(Humanities and Social Sciences) 6: 1-8.

Liping, Sun. 2005. Social Transformation: the New Issue on Sociology of Development. Sociological Studies 1: 1-24.

Lu, Huilin. 2015. The Road Leading to The Collective: A Case Study on the Formation of Cultural Concept and Institution. Beijing: Social Sciences Academic Press.

Lulu, Li. 2002. A Discussion on Unit (danwei) Studies. Sociological Studies 5: 23-32.

Meyer, J, and B Rowan. 1977. Institutionalized Organizations: Formal Structure as Myth and Ceremony. American Journal of Sociology 83: 340-363.

Meyer, J, and B Rowan. 1978. The Structure of Educational Organizations. In Environments and Organizations: Theoretical and empirical perspectives(pp, ed. MW Meyer, 78-109. San Francisco: Jossey-Bass, Inc.

Morris, MW, YY Hong, CY Chiu, and Z Liu. 2015. Normology: Integrating Insights about Social Norms to Understand Cultural Dynamics. Organizational Behavior and Human Decision Processes 50: 1-13.

Ogburm, WF. 1922. Social Change with Respect to Culture and Original Nature. Nature.B.W. Huebsch, inc.

Prasenjit, Duara. 2010. "Culture, Power and The State," Wang Fuming (Trans.). Nanjing: Jiangsu People's Publishing Ltd.

Scott, JC. 2011. "Weapons of the Weak", ZhengGuanghuai, Zhang Min, He Jiangsui (trans.). Nanjing: Phoenix Publishing \& Media Group, Yilin Press.

Shizheng, Feng. 2012. State Power Building and New China Petition Institution's Formation and Evolution. Sociological Studies 4: 25-47.

Wan, C, and CY Chiu. 2009. "An Intersubjective Consensus Approach to Culture: The Role of Intersubjective Norms versus Cultural Self in Cultural Processes". In Understanding Culture: Theory, Research, and Application, ed. RS Wyer, CY Chiu, and YY Hong. New York, London: Psychology Press.

Wang, Yuesheng. 1993. The Outline of Relationship between Traditional Culture and Chinese Population. Chinese Journal of Population Science 5: 20-27.

Wang, Huijun. 2011. Analysis on the Fertility Problem of Urban Professional Women-A Case Study on Three Professional Women in Harbin. Labor Security World 3: 90-91.

Weidong, Li, and Shang Zijuan. 2012. The Production and Reproduction of Son Preference as A Reproductive Culture. Collection of Women's Studies 3: 36-43.

Weiwen, Zhou. 1994. The Impact of Role Conflict of Contemporary Career Women on the Change of Female Fertility Pattern. Hebei Academic Journal 3: 97-102.

Wu, Xiaoyan. 2011. From Culture Building to Community Identity: The Governance of Village-turned-community Communities. Journal of Central China Normal University (Humanities and Social Sciences) 5: 9-15.

Wu, Ying, and Yiyin Yang. 2013. Society and Individuals' Mutual Construction in Social Psychology's Formation-The Inspiration of Theory 'Consensus' on Social Psychology Research. Social Science Front 2: 159-166.

Xie, Lihua. 2010. My Birth Story. Beijing: SDX Joint Publishing Company.

Xinhua, Sun. 2012. A Further Study of the Late Second Childbearing by a Comparison among Three Towns in H Province. South China Population 1: 1-9.

Xinxiang, Chen. 2004. An Approach to Social Practice from Birth Control in Chen Cun Village. Sociological Studies 3 93-102.

Yan, Yunxiang. 2006. "Private Life under Socialism: Love, Intimacy, and Family Change in a Chinese Village, 1949-1999", Gong Xiaoxia (Trans.). Shanghai: Shanghai Bookstore Publishing House.

Yang, Shanhua, and Zhao Litao. 1996. Reconstruction of Community Order in the Transformation of Rural China: An Investigation on the Interaction Structure of 'Farmer-Community' in Institutional Context. Sociological Studies 5: $64-75$.

Yingying, Ji. 2012. Culture, Institution and Structure: Reflections on the Studies of Chinese Social Relations". Sociological Studies 2: 60-85.

Yinhe, Li. 2009. Fertility and Village Culture. Hohhot: Inner Mongolia University Press.

You, Danzhen, and Zhenzhen Zheng. 2002. "An Analysis on Fertility Desire of Rural-Urban Migrant Women: An Empirical Research in Sichuang and Anhui Provinces". Sociological Studies 6: 52-62.

Yusheng, Peng. 2009. When Formal Laws and Informal Norms Collide: Birth Control Policy and Lineage Networks. Society 1: 37-65.

Zhang, Nan, and Siqing Peng. 2015. "Cultural Change in Cultural Mash up - Probing into Processes and Effects". In Chinese Social Psychological Review, Vol. 9th ed, ed. Chi-yue Chiu and Ying Wu. Beijing: Social Sciences Academic Press.

Zhen, Chen, and Chen Junjie. 1997. Cultural Marginality of Farmer's Fertility. Population Research 6: 18-25.

Zhu, Xufeng. 2011. Behavioral Patterns of Expert Participation in Social Policy Changes in China. sociological studies 2: 1-27.

Zhu, Chuzhu, and Li Shuzhuo. 1997. The Dual Effects of the Family Planning Program on Chinese Women. Population and Economy 4: 3-9.

Zongzhi, Huang. 2001. Law, Society and Culture in Qing Dynasty: The Expression and Practice of Civil Law. Shanghai: Shanghai Bookstore Publishing House. 